\title{
DESENVOLVIMENTO DE ESCALA PARA MEDIÇÃO DA GOVERNANÇA CORPORATIVA EMPREENDEDORA
}

\section{SCALE DEVELOPMENT TO MEASURE ENTREPRENEURIAL CORPORATE GOVERNANCE}

\section{DESARROLLO A ESCALA PARA MEDIR EL GOBIERNO CORPORATIVO EMPRESARIAL}

\section{Renan Grijó Búrigo}

Doutorando em Administração no Centro de Ciências da Administração e Socioeconômicas (ESAG) da Universidade do Estado de Santa Catarina (UDESC)

Endereço: Av. Madre Benvenuta, n. 2037, Bairro Itacorubí, CEP: 88.035-001. Florianópolis, SC, Brasil E-mail: rburigo@gmail.com

Fone: (48) 99127-5364

\section{Nério Amboni}

Doutor em Engenharia da Produção pela Universidade Federal de Santa Catarina (UFSC)

Professor e pesquisador no ESAG/UDESC

Endereço: Av. Madre Benvenuta, n. 2037, Bairro Itacorubí, CEP: 88.035-001. Florianópolis, SC, Brasil

E-mail: nerio.amboni@udesc.br

Fone: (48) 99922-8770

\section{Rafael Bassegio Caumo}

Doutorando em Engenharia e Gestão do Conhecimento (PPGEGC) na Universidade Federal de Santa Catarina (UFSC)

Professor no ESAG/UDESC

Endereço: R. João Pacheco da Costa, n. 855. Florianópolis, SC, Brasil

E-mail: rbcaumo@gmail.com

Fone: (48) 99910-0116

\section{Rafael Tezza}

Doutor em Engenharia de Produção pela UFSC

Professor e pesquisador no ESAG/UDESC e do Programa de Pós-Graduação em Métodos e Gestão em Avaliação (INE/UFSC)

Endereço: Av. Madre Benvenuta, 2037, Bairro Itacorubí, Florianópolis / SC

CEP: 88.035-001

E-mail: rafael.tezza@udesc.br

Fone: (48) 36648255

Artigo recebido em 29/12/2019. Revisado por pares em 12/01/2020. Reformulado em 15/01/2020. Recomendado para publicação em 03/04/2020. Publicado em 30/04/2020. Avaliado pelo Sistema double blind review.

CCopyright 2020 UNISUL-PPGA/Revista Eletrônica de Estratégia \& Negócios. Todos os direitos reservados. Permitida citação parcial, desde que identificada a fonte. Proibida a reprodução total. Revisão gramatical, ortográfica e ABNT de responsabilidade dos autores. 


\section{RESUMO}

O artigo teve por objetivo desenvolver uma escala para mensuração da Governança Corporativa Empreendedora em empresas brasileiras de capital fechado, a partir dos construtos governança corporativa e orientação empreendedora. Os dados foram coletados via questionário com 300 empresas brasileiras de capital fechado e foi utilizada a análise fatorial exploratória para construção da escala. Ao final dos testes estatísticos, ocorreu o agrupamento dos 24 itens da escala em três dimensões (transparência/prestação de contas, responsabilidade corporativa e equidade), diferente das quatro dimensões apresentadas pela literatura.

Palavras chave: Governança corporativa; Orientação empreendedora; Escala para medição da governança.

\section{ABSTRACT}

The article aimed to develop a scale for measuring entrepreneurial corporate governance in privately held Brazilian companies, based on the constructs corporate governance and entrepreneurial orientation. Data were collected via a questionnaire with 300 privately held Brazilian companies and the exploratory factor analysis was used to build the scale. At the end of the statistical tests, the 24 items of the scale were grouped in three dimensions (transparency/accountability, corporate responsibility and equity), different from the four dimensions presented in the literature.

Keywords: Corporate governance; Entrepreneurial orientation; Scale to measure entrepreneurial.

\section{RESUMEN}

El artículo tenía como objetivo desarrollar una escala para medir el gobierno corporativo empresarial en empresas privadas brasileñas, basado en los conceptos de gobierno corporativo y orientación empresarial. Los datos se recopilaron mediante un cuestionario con 300 empresas brasileñas privadas y se utilizó el análisis factorial exploratorio para construir la escala. Al final de las pruebas estadísticas, los 24 ítems de la escala se agruparon en tres dimensiones (transparencia/responsabilidad, responsabilidad corporativa y equidad), diferentes de las cuatro dimensiones presentadas en la literatura.

Palabras clave: Gobierno corporativo; Orientación emprendedora; Escala para medir el gobierno corporativo. 


\section{INTRODUÇÃO}

A Governança Corporativa (GC) surgiu com força ao longo das últimas décadas, na pauta das revistas acadêmicas de gestão, com publicações dos mais variados temas, como normas e diretrizes de países para sua implementação, melhores práticas e escalas e índices para auferi-la nas organizações. O interesse pelo tema foi motivado, de um lado, pelos escândalos corporativos, protestos públicos, pela elevada remuneração executiva e pelas crises financeiras da Ásia, Rússia e Brasil (CHRISTOPHER, 2010; CLAESSENS; YURTOGLU, 2013; DORFF, 2014) e, de outro, porque a GC desempenha um papel fundamental na alocação de recursos e na definição de responsabilidades, afetando as escolhas estratégicas, a criação e a distribuição de valor nas organizações (CUERVO-CAZURRA; RAMAMURTI, 2017; AGUILERA; MARANO; HAXHI, 2019).

A GC representa um meio essencial para criar um ambiente de mercado de confiança e de integridade comercial, assim como serve de apoio ao desenvolvimento do mercado de capitais e ao acesso ao capital próprio para investimentos produtivos a longo prazo (OECD, 2019). De fato, a qualidade da estrutura de GC das organizações é decisiva para motivar a Orientação Empreendedora (OE) das firmas (TYLECOTE; VISINTIN, 2007; CALZA; PROFUMO; TUTORE, 2017). A OE de uma organização é verificada nas situações em que os gestores do topo estiverem inclinados a assumir riscos relacionados com o negócio (risco), a favor da mudança e da inovação para obterem vantagens competitivas (inovação), além de competirem de forma agressiva com outras organizações (proatividade) (COVIN; SLEVIN, 1988). Lumpkin e Dess (1996) ampliaram o domínio do conceito com a inclusão de duas dimensões adicionais (autonomia e agressividade competitiva), resultando em cinco dimensões: autonomia, inovatividade, propensão ao risco, proatividade e agressividade competitiva.

A relação entre os construtos de $\mathrm{GC}$ e $\mathrm{OE}$ é demonstrada, ao longo dos anos, nas publicações do Instituto Brasileiro de Governança Corporativa (IBGC) nas publicações da Organisation for Economic Co-operation and Development (OECD) (IBGC, 2015; 2018; OECD, 2015; 2019). Outros estudos também ratificam o tema, como: Tylecote e Visintin (2007), verificaram que a GC é um dos principais determinantes da inovação e da mudança tecnológica; Eling e Marek (2014) descobriram que o aumento na remuneração e no Revista Eletrônica de Estratégia \& Negócios, Florianópolis, v.13, n. 1, jan./abr. 2020. 
monitoramento na estrutura de GC reduzia a tendência de propensão aos riscos; Molokwu, Barreria e Urban, (2013) identificaram que os mecanismos de GC possuíam uma correlação significativa e positiva com as dimensões de OE (inovação, presunção ao risco e proatividade); Calza, Profumo e Tutore $(2016,2017)$ constataram que a estrutura de propriedade influencia na proatividade ambiental das empresas pesquisadas e Asensio-López, Cabeza-García e González-Álvarez (2019) chegaram à conclusão de que a potencialização das dimensões (inovação, autonomia, proatividade, competitividade e propensão ao risco), depende de fatores que são influenciados pelos mecanismos de GC, tais como a estrutura de propriedade, a identidade do acionista ou a forma de funcionamento da conselho administrativo.

Apesar da reconhecida importância da GC para as organizações e dos esforços e da sofisticação de medidas e métodos, os resultados ainda são ambíguos e contraditórios, evidenciando a não existência de nenhuma medida de GC aceitável em todo o mundo (BHAGHAT: BOLTON, 2008; AGUILERA et al. 2008; OECD, 2019).

A busca por medidas e métodos mais sofisticados para avaliar a GC, incentivou o desenvolvimento de diferentes tipos de escalas para este mesmo objetivo, porém, embasadas em diferentes vertentes literárias e paradigmáticas. Embora exista inúmeras escalas para medição do construto em questão, pode-se agrupá-las em três tipos: a) escalas comerciais (são desenvolvidas por empresas de consultorias que, geralmente, vendem um diagnóstico de análise de GC) (DAINES; GOW; LARCKER, 2010; NERANTZIDIS, 2016); b) escalas secundárias (são desenvolvidas para mensurar GC em empresas listadas em bolsas de valores, pois, estas emitem frequentemente relatórios contábeis e gerenciais, tornando-os públicos) (FERDOUS; RAHMAN, 2017) e; c) escalas primárias (são desenvolvidas por meio de itens associados aos mecanismos de GC para avaliar, segundo as percepções dos dirigentes da organização, ou dos membros do conselho de gestão, o nível de GC) (KALEZIĆ, 2012; RAMLY; 2013; JOSLIN; MULLER, 2016). Nesta linha, este artigo tem por objetivo desenvolver uma escala para medição da Governança Corporativa Empreendedora (GCE) em empresas brasileiras de capital fechado.

O artigo ganha relevância, em um primeiro momento, porque procura desenvolver uma escala para medir a GCE em organizações, a partir da conjugação dos conceitos de $\mathrm{OE}$ com os de GC. Em um segundo momento, o desenvolvimento da escala proporciona a 
verificação, com auxílio da Análise Fatorial Exploratória (AFE) e outros testes estatístico, de quais itens melhor representam as dimensões do construto GCE e devem ser excluídos, conforme discutido nos transcorrer deste artigo. Ainda, a originalidade do artigo é um ponto de destaque porque não foi identificado nenhum trabalho anterior, no Brasil, que tenha desenvolvido e validado escala, com aplicação de AFE, para mensuração da GCE em organizações brasileiras de capital fechado.

Os argumentos da introdução fazem parte da primeira seção. Em seguida, são discutidos os fundamentos teóricos acerca da GC e OE, assim como dos principais estudos realizados que verificaram a associação das dimensões da GC em relação as da OE. A seção três apresenta a metodologia utilizada no desenvolvimento de escala para medição de GCE em empresas brasileiras de capital fechado. A seção quatro descreve e discute os resultados dos testes estatísticos e apresenta a escala final de GCE. A seção cinco envolve as conclusões e a seis as referências utilizadas no desenvolvimento do artigo.

\section{GOVERNANÇA CORPORATIVA E ORIENTAÇÃO EMPREENDEDORA}

\subsection{GOVERNANÇA CORPORATIVA}

O uso do termo GC foi intensificado após as mudanças econômicas e políticas ocorridas em diversos países do globo, incluindo os membros da OECD, a partir de meados da década de 1980 (L'HUILLIER, 2014). Apesar destas movimentações, não há um consenso sobre uma "definição universalmente aceita" para GC, devido a diferença de contexto e especificidades de cada país e a sua característica de multidisciplinariedade, envolvendo áreas de contabilidade, direito, administração, responsabilidade social, dentre outras (AGUILERA; JACKSON, 2010; OSINSKI; ROMAN; PEREIRA, 2015; KOSTYUK; MOZGHOVYI; GOVORUN, 2018).

O Relatório Cadburg, publicado em 1992, ficou conhecido mundialmente por ser um relatório seminal, que define a base para uma estrutura de "melhores práticas" de GC no Reino Unido, surtindo reflexo em muitos países do mundo. Outros relatórios também enfatizaram assuntos relacionados a GC, tais como: o Relatório Greenbury (1995) que discutiu a remuneração dos diretores; o Relatório do Comitê Hampel (1998), que abordou além das questões enfatizadas nos Relatórios da Cadbury e Greenbury, os princípios da GC, o papel dos diretores, a remuneração dos diretores, o papel dos acionistas e a responsabilidade; o 
relatório Turnbull (1999), que enfatizou a implementação dos requisitos de controle interno e, em 2003, o relatório Higgs (2003), que se concentrou no papel de conselheiros não executivos (SOLOMON; SOLOMON, 2004; MALLIN, 2011). Existem alguns modelos diferentes de GC no mundo, como o Anglo-Americano, o Europeu continental - Alemão, o modelo Japonês, o modelo da OECD e o modelo brasileiro do IBGC.

O modelo anglo-saxão é o sistema de GC mais frequentemente encontrado nos EUA, Canadá, Austrália e no Reino Unido, representado por um conselho de nível único, integrado por vários diretores de fora da organização. Na literatura, o modelo tem recebido diferentes nomes, dentre os quais cabe destacar: modelo de acionistas, modelo americano, modelo anglo-americano, modelo centrado no mercado, modelo baseado na equidade, modelo do agente-principal, modelo externo e modelo financeiro (AGLIETTA; REBÉRIOUX, 2005; BLOCK; GERSTNER, 2016). Este modelo é representado por um triângulo composto por acionistas, conselho e administração. A propriedade das companhias está pulverizada (vários acionistas) com pouco poder individual, devido à pequena parcela de propriedade, onde os investimentos estão protegidos por um mercado acionário com alta liquidez e uma forte proteção legal aos acionistas minoritários. É um dos modelos menos burocráticos de GC, tornando-se uma escolha de governança popular entre as organizações de alto crescimento (AHMAD; OMAR, 2016).

Como no modelo americano, o modelo Alemão (Continental) evoluiu após grandes crises, como a Segunda Guerra Mundial. O poder de grupos centrais de partes interessadas, em especial os trabalhadores, foi reforçado em 1951, quando o governo introduziu a Lei de Gestão Cooperativa, que preparou o terreno para a abordagem cooperativa aos direitos dos acionistas e funcionários, na governança das organizações cotadas em bolsa. Mais tarde, na década de 1970, a Lei da co-determinação solidificou o papel dos trabalhadores na influência das organizações (FOHLIN, 2005; BOTTENBERG; TUSCHKE1; FLICKINGER, 2017). O princípio que fundamenta o sistema Continental de GC é o da teoria das partes interessadas da organização (teoria dos stakeholders). O modelo capitalista continental considera não apenas os interesses dos acionistas, mas a contribuição das partes interessadas relevantes: trabalhadores, gerentes, fornecedores, clientes, comunidade e outras (CERNAT, 2004; VASILESCU, 2008). 
O modelo Japonês segue, em linhas gerais, a conceituação epistêmica do modelo Continental e traz, como novo, o conceito de holding: grupos industriais compostos de organizações com interesses comuns e estratégias similares. A responsabilidade dos gerentes é manifestada nas relações com os acionistas e Keiretsu (rede de fornecedores leais e clientes). O Keiretsu representa um padrão complexo de cooperação e de competição de relacionamentos, caracterizados pela adoção de táticas defensivas em aquisições hostis, reduzindo o grau de oportunismo das partes envolvidas para manter relações comerciais de longo prazo (MCGUIRE; DOW, 2009; SAKAWA; MORIYAMA; WATANABEL, 2012).

Embora não exista consenso global sobre a definição de GC, a OECD protagoniza liderança neste quesito, pois, seu modelo e suas publicações de princípios auxiliam organizações de muitos países a desenvolverem melhores práticas, aproximando suas diretrizes a um conceito mundialmente aceito. Em 1999, a OECD publicou o manual "OECD Principles of Corporate Governance", onde afirma que a GC envolve um conjunto de relações entre a administração de uma empresa, sua diretoria, seus acionistas e outras partes interessadas. Este manual também fornece a estrutura onde os objetivos da empresa, e os meios para atingi-los e monitorá-los, são determinados. Em 2004, este manual de princípios sofreu atualização, mas, em 2015, no encontro do G20 em Antália na Turquia, foi editada a última versão do manual que ressalta que a GC não é um fim em si mesma. É um meio para apoiar a eficiência econômica, o crescimento sustentável e a estabilidade financeira das organizações (OECD, 2015).

No Brasil, o modelo do IBGC se posiciona como referência por desenvolver uma série de atividades, cursos e publicações a fim de aumentar o número de empresas que aplicam as melhores práticas de GC e por estimular o aprimoramento das que já utilizam. Desde a década de 1990, "O Código de Melhores Práticas de Governança Corporativa" é publicado com o propósito de auxiliar os gestores na implantação dos princípios de GC, descrito como o sistema pelo qual as empresas e demais organizações são dirigidas, monitoradas e incentivadas, envolvendo os relacionamentos entre sócios, conselho de administração, diretoria, órgãos de fiscalização e controle e demais partes interessadas (IBGC, 2009; 2015). 
Os princípios de GC estabelecidos pela OECD (2015) e pelo IBGC (2015) permeiam, em maior ou menor grau, todas as práticas e, sua adequada adoção, resulta em um clima de confiança tanto internamente quanto nas relações com terceiros (Quadro 1).

Quadro 1 - Princípios de Governança Corporativa

\begin{tabular}{|c|c|c|}
\hline Princípio & IBGC (2015) & OECD (2015) \\
\hline Transparência & $\begin{array}{l}\text { Consiste no desejo de disponibilizar } \\
\text { para as partes interessadas as } \\
\text { informações que sejam de seu } \\
\text { interesse, e não apenas aquelas } \\
\text { impostas por disposições de leis ou } \\
\text { regulamentos. Não deve restringir-se } \\
\text { ao desempenho econômico, } \\
\text { contemplando também os demais } \\
\text { fatores (inclusive intangíveis) que } \\
\text { norteiam a ação gerencial e que } \\
\text { conduzem à preservação e à otimização } \\
\text { do valor da organização. }\end{array}$ & $\begin{array}{l}\text { A estrutura de GC deve promover } \\
\text { mercados transparentes e justos, e a } \\
\text { alocação eficiente de recursos. Deve } \\
\text { estar de acordo com as leis e apoiar a } \\
\text { supervisão e fiscalização destas; }\end{array}$ \\
\hline Equidade & $\begin{array}{l}\text { Caracteriza-se pelo tratamento justo e } \\
\text { isonômico de todos os sócios e demais } \\
\text { partes interessadas (stakeholders), } \\
\text { levando em consideração seus direitos, } \\
\text { deveres, necessidades, interesses e } \\
\text { expectativas. }\end{array}$ & $\begin{array}{l}\text { A estrutura de GC deve proteger e } \\
\text { facilitar o exercício dos direitos dos } \\
\text { acionistas e garantir o tratamento } \\
\text { equitativo de todos os acionistas, } \\
\text { incluindo acionistas minoritários e } \\
\text { estrangeiros. Todos os acionistas } \\
\text { devem ter a oportunidade de obter } \\
\text { reparação efetiva por violação de seus } \\
\text { direitos; }\end{array}$ \\
\hline $\begin{array}{l}\text { Prestação de } \\
\text { contas } \\
\text { (accountability) }\end{array}$ & $\begin{array}{l}\text { Os agentes de governança devem } \\
\text { prestar contas de sua atuação de modo } \\
\text { claro, conciso, compreensível e } \\
\text { tempestivo, assumindo integralmente } \\
\text { as consequências de seus atos e } \\
\text { omissões e atuando com diligência e } \\
\text { responsabilidade no âmbito dos seus } \\
\text { papéis. }\end{array}$ & $\begin{array}{l}\text { A estrutura de GC deve assegurar que a } \\
\text { divulgação oportuna e precisa seja feita } \\
\text { em todos os assuntos materiais } \\
\text { relativos à corporação, incluindo a } \\
\text { situação financeira, desempenho, } \\
\text { propriedade e governança da empresa; }\end{array}$ \\
\hline $\begin{array}{l}\text { Responsabilidade } \\
\text { Corporativa }\end{array}$ & $\begin{array}{l}\text { Os agentes de governança devem zelar } \\
\text { pela viabilidade econômico-financeira } \\
\text { das organizações, reduzir as } \\
\text { externalidades negativas de seus } \\
\text { negócios e suas operações e aumentar } \\
\text { as positivas, levando em consideração, } \\
\text { no seu modelo de negócios, os diversos } \\
\text { capitais (financeiro, manufaturado, } \\
\text { intelectual, humano, social, ambiental, } \\
\text { reputacional, etc.) no curto, médio e } \\
\text { longo prazo. }\end{array}$ & 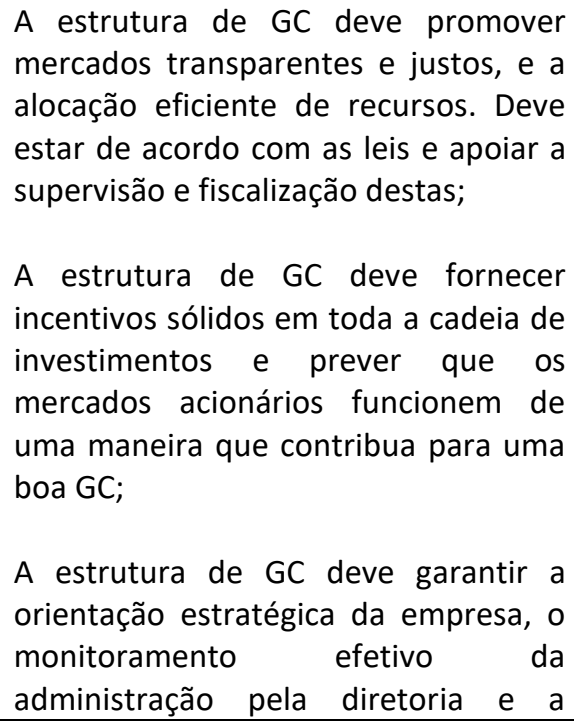 \\
\hline
\end{tabular}




\begin{tabular}{|l|l|l|}
\hline Princípio & \multicolumn{1}{|c|}{ IBGC (2015) } & \multicolumn{1}{c|}{ OECD (2015) } \\
\hline & $\begin{array}{l}\text { responsabilidade da diretoria perante a } \\
\text { empresa e os acionistas; }\end{array}$ \\
\hline
\end{tabular}

Fonte: Elaborado pelos autores, a partir de IBGC (2015) e OECD (2015).

Os autores Aguilera et al. (2008), Aguilera et al. (2015) e Garcia-Castro e Aguilera (2015), reforçam os Princípios da OECD e do IBGC, quando conceituam a GC como o meio pelo qual os direitos da empresa, dos acionistas e das partes interessadas são assegurados, para garantir que as partes atuem, de forma responsável na geração, proteção e na distribuição da riqueza investida na empresa, referindo-se à autoridade para dirigir, organizar e controlar a organização.

\subsection{ORIENTAÇÃO EMPREENDEDORA}

As raízes conceituais do termo de OE foram discutidas pelo Grupo de Aston, na década de 1960 (EDMOND; WIKLUND, 2010), e demonstra a propensão de um indivíduo/organização em ter a intenção empreendedora (ROBINSON et al., 1991). Assim, a OE representa um fator antecedente da intenção e da atitude empreendedora. Nesta linha, segundo Miller e Friesen (1982, p. 5), uma organização empreendedora é aquela "que inova com ousadia e regularidade, assumindo riscos consideráveis em suas estratégias de mercado de produtos". Proatividade e atitude também é essencial, ou seja, a OE pode ser resumida como a exposição simultânea de inovatividade, tomada de risco e proatividade (MILLER; FRIESEN, 1982, p. 5; MILLER, 1983).

Os autores Covin e Slevin $(1989,1991)$ expandiram os trabalhos de Miller e Friesen (1982) e de Miller (1983) quando discutiram diferentes "posturas" que poderiam ser empreendedoras ou conservadoras. Ainda, sugeriram que a OE era um contínuo que variava de conservador para empreendedor e que as organizações poderiam ser posicionadas em qualquer lugar no continuum. Miller (1983) possuía uma visão binária, uma organização é empreendedora ou não é.

Lumpkin e Dess (1996, p. 136), ampliaram o domínio do conceito com a inclusão de duas dimensões adicionais (autonomia e agressividade competitiva), resultando em cinco dimensões: autonomia, inovatividade, propensão ao risco, proatividade e agressividade competitiva. Ainda, complementam que as cinco dimensões da OE (Figura 01) podem ocorrer Revista Eletrônica de Estratégia \& Negócios, Florianópolis, v.13, n. 1, jan./abr. 2020. 
em diferentes combinações em uma organização, dependendo do tipo de oportunidade empreendedora que ela persegue. O quanto cada uma das dimensões é útil para predizer a natureza e o sucesso de um empreendimento pode ser contingente a fatores externos (como o ambiente de negócios), a fatores internos (como estrutura organizacional) ou a características dos fundadores ou líderes da organização.

Figura 01 - A arquitetura da orientação empreendedora

Inovação: traduz a vontade do gestor em introduzir novidades através da experimentação e processos criativos voltados para o desenvolvimento de novos processos, produtos e serviços.

Proatividade: traduz uma perspectiva voltada para o futuro. É uma característica de um líder de mercado, que procura aproveitar as oportunidades em antecipação às demandas futuras.

Propensão de riscos: tomar decisões sem um certo conhecimento de prováveis resultados; algumas organizações também podem envolver a realização de compromissos de recursos substanciais no processo de se aventurar em frente.

\section{Orientação Empreendedora}

Autonomia: ação independente de um indivíduo ou equipe com o objetivo de produzir um conceito ou visão de negócios e levá-lo até a conclusão.

Agressividade competitiva: um intenso esforço para superar os rivais da indústria. Caracteriza-se por uma postura ou por uma resposta agressiva destinada a melhorar a posição ou superar uma ameaça em um mercado competitivo.

Fonte: Adaptado de Wójcik-Karpacz (2016, p. 249), a partir de Covin e Slevin, 1989; Lumpkin e Dess, 1996; Miller,1983; Dess e Lumpkin, 2005.

Para Covin e Kuratko (2008), as organizações estão aumentando o seu compromisso com o empreendedorismo, a fim de sobreviverem em um ambiente de negócios dinâmico e hipercompetitivo. O sucesso e a sobrevivência em longo prazo das organizações podem ser alcançados, quando a OE se tornar um fenômeno em toda a organização, sobretudo com o estímulo e utilização da tecnologia. As organizações com tendência empreendedora se adaptam com mais facilidade aos caprichos do ambiente de negócios, aumentando assim suas chances de desempenho e sucesso superiores (WANG, 2008; MENDIETA et al, 2013). A OE ajuda a empresa a incubar ideias para produzir bens e serviços, participar de projetos de alto risco, prever necessidades futuras e descobrir novas oportunidades no mercado. É para Doorn et al. (2013), uma condição essencial para as empresas poderem competir em um ambiente Revista Eletrônica de Estratégia \& Negócios, Florianópolis, v.13, n. 1, jan./abr. 2020. 
econômico globalizado e, em mudança. A OE promove criatividade e inovações dentro das empresas (ENGELEN et al. 2015).

\subsection{GOVERNANÇA CORPORATIVA E ORIENTAÇÃO EMPREENDEDORA}

O estudo do impacto da GC, junto ao empreendedorismo e dimensões que caracterizam a OE das empresas, é notório e cresceu ao longo dos últimos anos, conforme demonstrado na publicação do “Manual de Análises e Tendências - Inovação” do IBGC (2018), na "OECD Corporate Governance Factbook" OECD (2019) e em outros trabalhos ao redor do globo (GONZALES-BUSTOS; HERNÁNDEZ-LARA, 2016).

Os mecanismos de GC representam, para Aguilera et al. (2008), uma plataforma para os conselhos e gerentes perseguirem os interesses dos acionistas e as metas organizacionais, através do uso eficiente dos recursos. Esse compromisso, extraído dos membros do conselho e dos gerentes, pode incentivar a inserção da OE dentro das organizações. Hashimoto e Nassif (2014), argumentam que as práticas de GC orientadas para a OE, somada a atitude do gerente, podem induzir os funcionários na adoção de comportamentos mais empreendedores. $\mathrm{O}$ apoio dos executivos seniores às iniciativas empreendedoras é maior, segundo Zahra, Neubaum e Huse (2000), quando um acionista representativo apostar e defender investimentos de longo prazo e primar pela cultura empreendedora.

Tan e Tan (2004), Gabrielsson e Huse (2004) e Hagen, Emmanuel e Alshare (2005), concluíram que os efeitos da GC dependem das práticas de GC em toda a organização e não somente em alguns setores/unidades. Conforme os autores, o envolvimento do conselho no controle de decisão afeta a postura empreendedora da organização, em termos de inovação em processos e inovação organizacional. Todavia, a influência dos mecanismos de GC na dimensão de inovação pode ser tanto uma relação de mão dupla, positiva ou negativa.

Dentre os autores que encontraram uma relação positiva dos mecanismos de GC na dimensão inovação, cabe destacar: Aghion, Van Reenen e Zingales (2013): uma ligação positiva entre o esforço de inovação das empresas dos EUA e a propriedade institucional; De Cleyn e Braet (2012): uma relação significativa e positiva entre a capacidade de inovação e o tamanho do conselho das 49 indústrias de fabricação belgas de pequeno e médio portes (PMEs); Shapiro et al. (2015): a GC e a propriedade das 370 empresas privadas de pequeno e Revista Eletrônica de Estratégia \& Negócios, Florianópolis, v.13, n. 1, jan./abr. 2020. 
médio porte analisadas da China, afetaram mais fortemente a atividade de inovação, quando a inovação era medida pela atividade de patenteamento e não em relação a venda de novos produtos; Sipos (2017): a GC apresentou um impacto significativo nas atividades de inovação das empresas dos 26 países emergentes europeus selecionados no estudo.

A influência da GC na inovação, como uma relação de mão dupla, também foi verificado por diferentes autores, dentre outros: Lee e O'Neill (2003): o aumento na concentração de propriedade estava positivamente relacionado com as despesas de pesquisa e desenvolvimento (inovação) em empresas dos EUA e não nas empresas japonesas; Hall e Oriani (2006): os investimentos em P\&D estavam positivamente relacionados ao valor de mercado nas empresas da França, Alemanha, Reino Unido e EUA. Mesmo nas empresas que não possuíam grandes acionistas, como nas empresas da Itália e França, também foram valorizadas positivamente no mercado devido as suas despesas de P\&D; Tseng et al. (2013): afirmam que há relação positiva entre o tamanho do quadro de diretores e a capacidade de inovação, e que a proporção de membros participando do conselho de administração é significativamente negativa em relação a capacidade de inovação, nas 255 empresas eletrônicas de Taiwan analisadas.

Por outro lado, a influência negativa da GC na inovação foi identificada por autores como: Hung e Mondejar (2005): a origem do conselho não teve efeitos significativos sobre as atividades inovadoras das empresas de uma grande cidade metropolitana asiática; Minetti, Murro e Paiella (2015): a concentração de propriedade das 20.000 fabricantes italianas analisadas, afetava negativamente a inovação, especialmente em termos de pesquisa e desenvolvimento. Os resultados evidenciaram que os conflitos de interesses dos grandes acionistas em relação aos minoritários foram determinantes na relação negativa da concentração acionária sobre a inovação. Estes achados confirmam os fundamentos da teoria da agência, discutida por Jensen e Meckling (1976) e Fama e Jensen (1983), de que os proprietários ou gerentes se tornam mais avessos aos riscos à medida que ocorrer o aumento da participação do seu capital na empresa (HESS, GUNASEKARAGE; HOVEY, 2010; SHAPIRO et al., 2015).

O relacionamento da $\mathrm{GC}$ com a inovação é uma questão importante no meio acadêmico, e que desperta o interesse de vários pesquisadores e gestores em estudar Revista Eletrônica de Estratégia \& Negócios, Florianópolis, v.13, n. 1, jan./abr. 2020. 
também os impactos dos mecanismos de GC nas outras dimensões que fundamentam a OE, como a proatividade, propensão ao risco, autonomia e agressividade competitiva. Segundo o IBGC (2018, p. 6) "É necessário que a prática da inovação esteja intrinsecamente inserida na cultura organizacional da empresa e, consequentemente, na sua estrutura de governança". A potencialização das dimensões da OE, segundo Asensio-López, Cabeza-García e GonzálezÁlvarez (2019), depende de fatores que são influenciados pelos mecanismos de GC, tais como: a estrutura de propriedade, a identidade do acionista ou da forma de funcionamento do conselho administrativo.

Outros trabalhos relevantes, realizados com o intuito de verificar a influência da GC nas dimensões da OE, são: Hung e Mondejar (2005): a dualidade do Chief Executive Officer (CEO) e presidente do conselho e os acionistas que são conselheiros das empresas analisadas, de uma grande cidade metropolitana asiática, influenciavam positivamente a preferência pela tomada de risco e o desenvolvimento de novas iniciativas; Hanazaki e Liu (2007): as empresas controladas pela família, nos cinco países do Leste Asiático (Indonésia, Coréia, Malásia, Filipinas e Tailândia), restringiam os investimentos e as preferências de risco analisadas; Anderson, Melanson e Maly (2007): os 658 diretores corporativos pesquisados da Austrália, Canadá, Nova Zelândia e Estados Unidos e os 34 investidores institucionais do Canadá, apontaram uma relação significativa entre a eficácia do conselho, envolvimento e conhecimento com as dimensões de inovatividade e propensão ao risco; Molokwu, Barreria e Urban (2013): os mecanismos de GC (eficácia do conselho; conhecimento e experiência do conselho; comprometimento do conselho e o envolvimento do conselho no controle de decisões) possuíam uma correlação significativa e positiva com as dimensões de OE (inovação, propensão ao risco e proatividade); Calza, Profumo e Tutore (2016, 2017): uma forte relação positiva entre a estrutura de propriedade com a proatividade ambiental e um impacto negativo e significativo da relação entre concentração de propriedade em relação a adoção de estratégias ambientais proativas e de que as maiores participações mantidas pelos investidores institucionais não estavam relacionadas à proatividade ambiental das empresas analisadas da Europa, incluídas no Caron Disclosure Project 2012; Olori e Sylva (2017): os mecanismos de GC (a eficácia, o conhecimento, o comprometimento e o envolvimento das diretorias) estavam positivamente relacionados com a inovatividade e a proatividade; 
enquanto a propensão ao risco apresentou uma moderada associação positiva com eficácia, conhecimento e comprometimento e, negativa com o envolvimento.

A dimensão competitividade agressiva também é desafiada pelos mecanismos de GC, pois, reflete o desejo da empresa ser pouco convencional, em vez de perpetuar os métodos tradicionais de competição (LUMPKIN; DESS, 1996). Zhang e Gimeno (2016), constataram que: a pressão sobre os ganhos refletia em impacto negativo sobre a agressividade da concorrência nas companhias aéreas que possuem maior quantidade de investidores institucionais transitórios e orientados a curto prazo, quando comparadas com as companhias aéreas que possuem investidores institucionais dedicados e orientados a longo prazo. Os achados da pesquisa de Zhang e Gimeno (2016) são consistentes com os argumentos de Chevalier (1995), de que a pressão sobre os ganhos incentiva o comportamento gerencial míope. Benner (2010) e Benner e Ranganathan (2012), também verificaram que os analistas de valores mobiliários orientavam os gerentes para reduzir o investimento estratégico ou para reagirem lentamente diante das tecnologias disruptivas.

Os estudos citados demonstram que os mecanismos de GC podem, dependendo do contexto interno e externo das empresas e da atitude gerencial, estimular de forma positiva, negativa e/ou em uma relação de mão dupla, a inovação, a proatividade, a autonomia, a propensão ao risco e a competitividade. Na seção a seguir, a metodologia utilizada na condução deste estudo é apresentada.

\section{METODOLOGIA}

A seção apresenta a metodologia utilizada no desenvolvimento de uma escala de medição de Governança Corporativa Empreendedora em empresas brasileiras de capital fechado, a partir dos fundamentos estatísticos discutidos por Pasquali (1999), Rossiter (2002), Hair Jr et al. (2009) e DeVellis (2017).

A versão inicial da escala foi elaborada com base nos conceitos/princípios de GC contidos no Manual de GC da OECD (2015), no Código das Melhores Práticas de GC do IBGC (2015), assim como nos fundamentos discutidos por Lumpkin e Dess (1996) sobre a OE. Os conceitos de GC orientaram a elaboração dos itens, pois, a escala foi concebida sob o preceito de que a OE está contida nos conceitos de GC.

Revista Eletrônica de Estratégia \& Negócios, Florianópolis, v.13, n. 1, jan./abr. 2020. 
Inicialmente foi desenvolvida uma escala, a partir dos conceitos apresentados pela teoria de GC, com itens divididos entre as quatro dimensões propostas. Estes itens foram analisados pelos pesquisadores para verificação de coerência, consistência e dubiedade. Também, a escala foi avaliada e associada aos conceitos de OE, a fim de verificar se os itens de GC refletiam características das dimensões de OE apresentadas por Lumpkin e Dess (1996). Em seguida, a escala foi submetida a análise de 5 especialistas, sendo 1 professor, 1 membro do IBGC e 3 executivos envolvidos com GC. Estes, analisaram os 50 itens, classificando-os em "Alta relevância", "Moderada relevância”, "Baixa relevância” e "Pregunta não está clara".

Após esta classificação, os autores atribuíram pesos de 4, 3, 2 e 1, as respostas dos especialistas, sendo 4 - "Alta relevância" e assim sucessivamente até 1 - "Pergunta não está clara". Para identificar quais itens eram relevantes, na visão dos especialistas, os pesquisadores estabeleceram uma linha de corte, ou seja, os itens deveriam ter, no mínimo, 2 especialistas que respondessem a opção "Alta relevância". Desta forma, os itens com valores de 16 ou menos pontos foram excluídos, resultando em 25 itens ao todo (Quadro 02). Em seguida, a escala foi submetida ao comitê de ética da universidade, obtendo aprovação para uso na pesquisa.

Quadro 02 - Itens aprovados pelos especialistas por dimensões dos conceitos teóricos de OE e GC

\begin{tabular}{|c|c|c|c|c|}
\hline Código & $\begin{array}{l}\text { Pontuação } \\
\text { dos } \\
\text { especialistas }\end{array}$ & Itens & $\begin{array}{l}\text { Dimensões de } \\
\text { OE }\end{array}$ & $\begin{array}{l}\text { Dimensões de } \\
\text { GC }\end{array}$ \\
\hline Q1 & 19 & $\begin{array}{l}\text { Disponibiliza informações extras, para as } \\
\text { partes interessadas, além daquelas } \\
\text { impostas por leis / regulamentos. }\end{array}$ & Proatividade & \multirow{5}{*}{ Transparência } \\
\hline Q2 & 19 & $\begin{array}{l}\text { Facilita, as partes interessadas, o acesso } \\
\text { a dados relevantes. }\end{array}$ & $\begin{array}{l}\text { Propensão ao } \\
\text { Risco }\end{array}$ & \\
\hline Q3 & 17 & $\begin{array}{l}\text { Preza pela aplicação integral do código } \\
\text { de ética. }\end{array}$ & Proatividade & \\
\hline Q4 & 17 & $\begin{array}{l}\text { Permite que as empresas de auditoria } \\
\text { independente auditem processos e } \\
\text { dados além dos exigidos por lei. }\end{array}$ & $\begin{array}{l}\text { Autonomia / } \\
\text { Proatividade }\end{array}$ & \\
\hline Q5 & 17 & $\begin{array}{l}\text { Desenvolve calendário anual para as } \\
\text { principais reuniões. }\end{array}$ & $\begin{array}{l}\text { Autonomia / } \\
\text { Proatividade }\end{array}$ & \\
\hline Q6 & 17 & $\begin{array}{l}\text { Apresenta, as partes interessadas, } \\
\text { resultados financeiros extras, além dos } \\
\text { obrigatórios. }\end{array}$ & $\begin{array}{l}\text { Propensão ao } \\
\text { Risco }\end{array}$ & \multirow{2}{*}{$\begin{array}{l}\text { Prestação de } \\
\text { contas }\end{array}$} \\
\hline Q7 & 17 & $\begin{array}{l}\text { Apresenta, as partes interessadas, os } \\
\text { resultados operacionais, incluindo os } \\
\text { resultados com inovações e melhoria } \\
\text { contínua. }\end{array}$ & $\begin{array}{l}\text { Proatividade / } \\
\text { Inovatividade }\end{array}$ & \\
\hline
\end{tabular}

Revista Eletrônica de Estratégia \& Negócios, Florianópolis, v.13, n. 1, jan./abr. 2020. 


\begin{tabular}{|c|c|c|c|c|}
\hline Q8 & 18 & $\begin{array}{l}\text { Apresenta, as partes interessadas, os } \\
\text { objetivos comerciais, incluindo os } \\
\text { objetivos de inovação e novos negócios. }\end{array}$ & $\begin{array}{l}\text { Agressividade } \\
\text { Competitiva }\end{array}$ & \\
\hline Q9 & 18 & $\begin{array}{l}\text { Apresenta, as partes interessadas, os } \\
\text { riscos operacionais e estratégicos. }\end{array}$ & $\begin{array}{l}\text { Propensão ao } \\
\text { Risco }\end{array}$ & \\
\hline Q10 & 18 & $\begin{array}{l}\text { Contrata auditoria externa independente } \\
\text { para análise das demonstrações } \\
\text { financeiras. }\end{array}$ & $\begin{array}{l}\text { Propensão ao } \\
\text { Risco }\end{array}$ & \\
\hline Q11 & 18 & $\begin{array}{l}\text { Desenvolve práticas em busca } \text { de } \\
\text { melhoria contínua observando as } \\
\text { inovações do mercado. }\end{array}$ & $\begin{array}{l}\text { Agressividade } \\
\text { Competitiva / } \\
\text { Inovatividade }\end{array}$ & \multirow{10}{*}{$\begin{array}{l}\text { Responsabilid } \\
\text { ade } \\
\text { corporativa }\end{array}$} \\
\hline Q12 & 19 & $\begin{array}{l}\text { Procura reduzir as externalidades } \\
\text { negativas de seus negócios. }\end{array}$ & $\begin{array}{l}\text { Agressividade } \\
\text { Competitiva }\end{array}$ & \\
\hline Q13 & 19 & $\begin{array}{l}\text { Procura aumentar as externalidades } \\
\text { positivas de seus negócios. }\end{array}$ & $\begin{array}{l}\text { Agressividade } \\
\text { Competitiva }\end{array}$ & \\
\hline Q14 & 18 & $\begin{array}{l}\text { Desenvolve o planejamento estratégico } \\
\text { voltado para a inovação. }\end{array}$ & Inovatividade & \\
\hline Q15 & 17 & $\begin{array}{l}\text { Acompanha, de forma sistemática, as } \\
\text { práticas e inovações do mercado. }\end{array}$ & Inovatividade & \\
\hline Q16 & 17 & $\begin{array}{l}\text { Estimula o desenvolvimento de ideias e } \\
\text { projetos de inovação. }\end{array}$ & $\begin{array}{l}\text { Inovatividade } \\
\text { / Proatividade }\end{array}$ & \\
\hline Q17 & 18 & $\begin{array}{l}\text { Garante a funcionalidade dos sistemas de } \\
\text { gerenciamento de riscos. }\end{array}$ & $\begin{array}{l}\text { Propensão ao } \\
\text { Risco }\end{array}$ & \\
\hline Q18 & 18 & $\begin{array}{l}\text { Busca, constantemente, inovações para } \\
\text { aperfeiçoar os sistemas de controles. }\end{array}$ & Inovatividade & \\
\hline Q19 & 19 & $\begin{array}{l}\text { Estimula todos os colaboradores a } \\
\text { trabalharem de forma alinhada com as } \\
\text { estratégias da empresa. }\end{array}$ & Autonomia & \\
\hline Q20 & 17 & $\begin{array}{l}\text { Estimula a participação de membros } \\
\text { independentes no conselho. }\end{array}$ & Autonomia & \\
\hline Q21 & 18 & $\begin{array}{l}\text { Trata todos os grupos de } \\
\text { acionistas/sócios da mesma forma. }\end{array}$ & Autonomia & \multirow{5}{*}{ Equidade } \\
\hline Q22 & 17 & $\begin{array}{l}\text { Leva em conta as sugestões das partes } \\
\text { interessadas no desenvolvimento de } \\
\text { novas tecnologias / produtos / serviços. }\end{array}$ & Proatividade & \\
\hline Q23 & 17 & $\begin{array}{l}\text { Considera, na avaliação de desempenho } \\
\text { dos executivos e diretores, a atitude e o } \\
\text { pensamento inovador. }\end{array}$ & $\begin{array}{l}\text { Autonomia / } \\
\text { Inovatividade }\end{array}$ & \\
\hline Q24 & 18 & $\begin{array}{l}\text { Garante os direitos e deveres das partes } \\
\text { interessadas. }\end{array}$ & Autonomia & \\
\hline Q25 & 17 & $\begin{array}{l}\text { Permite que todos os acionistas / sócios } \\
\text { votem nas assembleias / reuniões } \\
\text { estratégicas. }\end{array}$ & $\begin{array}{l}\text { Autonomia / } \\
\text { Agressividade } \\
\text { Competitiva }\end{array}$ & \\
\hline
\end{tabular}

Fonte: Elaborado pelos autores (2019).

Para aplicação junto a população, foi optado por utilizar escala adjetival com 4 pontos, com as seguintes opções: "Sempre", "Às vezes", "Raramente", "Nunca" ou "Prefiro não responder". Em seguida, a escala foi aplicada como pré-teste junto a 8 respondentes, a fim de garantir que as perguntas estavam claras, objetivas e compreensíveis. Todos os respondentes entenderam as perguntas e validaram a escala como se apresentava, com as 25 questões finais (Quadro 02). 
Esta pesquisa utiliza, como público alvo, membros de conselho de administração, presidentes, diretores, gerentes e/ou proprietários de empresas de capital fechado brasileiras. Os dados da pesquisa foram coletados por meio da aplicação da escala junto a população, por e-mail, contendo o Termo de Consentimento Livre e Esclarecido (TCLE) e o link de acesso ao GoogleForms para preenchimento. Entre os dias 1 de agosto a 13 de setembro, foram enviados cerca de 5 mil e-mails a empresas/executivos, sendo 2 mil associados do IBGC e 3 mil contatos diretos dos pesquisadores. A coleta foi encerrada quando da obtenção de 300 respondentes válidos.

Um aspecto importante na AFE é o tamanho e a qualidade da amostra. O tamanho mínimo aceitável é 5 vezes o número de variáveis envolvidas na análise sendo, mais adequado, 10 vezes. Alguns autores ainda sugerem 300 respondentes como um número ideal. A qualidade da amostra também é importante, tendo em vista que a escala deve ser aplicada junto as pessoas que tenham conhecimento e envolvimento com o tema em questão (TABACHNICK; FIDELL, 1996; HAIR JR et al., 2009; DEVELLIS, 2017).

As empresas pesquisadas foram caracterizadas por porte, área de atuação e localidade, como segue: a) porte: 257 são pequenas (faturamento de até 20 milhões de Reais); 28 médias (faturamento de 20 a 100 milhões de Reais); 10 médias-grande (faturamento de 100 a 400 milhões de Reais) e 5 grandes empresas (faturamento acima de 400 milhões de Reais); b) área de atuação: 163 atuam em serviços, 49 em indústria, 34 em comércio, 29 em tecnologia, 20 em saúde e 5 no setor primário; c) 90 empresas estão localizadas no estado de São Paulo; 73 em Santa Catarina, 34 em Minas Gerais e as 103 restantes estão em 16 diferentes estados do Brasil.

Os dados coletados foram tratados por meio dos testes estatísticos Kaiser-Meyer-Olkin (KMO), extração dos componentes principais, Parallel Analysis, AFE, o Alpha de Cronbach de cada dimensão e Composite Reliability (CR). Todos os testes estatísticos foram realizados no software Statistical Package for the Social Sciences (SPSS).

\section{RESULTADOS E DISCUSSÃO - ANÁLISE FATORIAL EXPLORATÓRIA}

Para verificar a adequação da AFE ao conjunto de dados coletados, foi calculado o índice KMO, com variação entre 0 e 1 . Nesta pesquisa foi obtido um resultado de 0,916, Revista Eletrônica de Estratégia \& Negócios, Florianópolis, v.13, n. 1, jan./abr. 2020. 
significativo ao nível de 0,05. Segundo Kaiser (1958) e Pasquali (1999), KMO acima de 0,9 é considerado excelente para utilização do teste estatístico proposto.

O teste de esfericidade de Bartlett possui significância, com P-value $<0,01$. Assim, rejeitamos a hipótese nula, indicando que é muito provável que haja correlação entre os itens (PESTANA; GAGEIRO, 2005; FÁVERO, 2009).

Para a identificação da quantidade de dimensões do modelo, foi utilizado o método de componentes principais e utilizado o critério de análise Parallel Analysis que, segundo DeVellis (2017), é o método mais indicado para identificação de dimensões. Segundo o modelo, o número de dimensões ideal é verificado quando o autovalor fica acima do valor da média e, segundo os dados levantados, são sugeridas 3 dimensões (Quadro 3). A variância acumulada do autovalor $>0,50$, alcançou 52,99\% na terceira dimensão, sugerindo também a utilização de apenas 3 dimensões.

Quadro 03 - Parallel Analysis

\begin{tabular}{lccc}
\hline Dimensão & Autovalor & Média & Variância acumulada \\
\hline $\mathbf{1}$ & 9,59 & 1,56 & $38,36 \%$ \\
$\mathbf{2}$ & 2,07 & 1,47 & $46,64 \%$ \\
$\mathbf{3}$ & 1,58 & 1,41 & $52,99 \%$ \\
\hline
\end{tabular}

Fonte: Elaborado pelos autores (2019).

A verificação das cargas fatoriais dos itens foi realizada pela análise de componentes principais, com rotação Varimax. Após a verificação dos escores das cargas fatoriais, foi identificado que o item Q3 ficou com carga < 0,300 das 3 dimensões propostas pelo modelo. Este mesmo item havia apresentado o menor valor na matriz de comunalidade, com 0,237. Desta forma, optou-se por excluir o item e refazer a análise com os 24 itens restantes, conforme apresentado no Quadro 04. 
Quadro 04 - Modelo de Componentes Principais com rotação Varimax e normalização de Kaiser com a Comunalidade observada e o Alpha de Cronbach por dimensão.

\begin{tabular}{|c|c|c|c|c|c|}
\hline Item & $\begin{array}{l}\text { Dimensão } 1 \text { - } \\
\text { Responsabilidade } \\
\text { Corporativa }\end{array}$ & $\begin{array}{l}\text { Dimensão } 2 \text { - } \\
\text { Prestação de } \\
\text { contas / } \\
\text { Transparência }\end{array}$ & $\begin{array}{c}\text { Dimensão } 3 \text { - } \\
\text { Equidade }\end{array}$ & Comunalidade & $\begin{array}{l}\text { Alpha de } \\
\text { Cronbach }\end{array}$ \\
\hline Q15 & ,726 & & & ,577 & \\
\hline Q11 & ,713 & & &, 587 & \\
\hline Q12 & ,712 & & &, 555 & \\
\hline Q16 & 704 & & & 633 & \\
\hline Q14 & 700 & & & 610 & 0,902 \\
\hline Q18 & 697 & & & ,592 & \\
\hline Q13 & ,682 & & &, 523 & \\
\hline Q17 & 677 & & & ,566 & \\
\hline Q19 & ,552 & & & ,593 & \\
\hline Q6 & & 679 & & ,647 & \\
\hline Q7 & & 667 & & ,742 & \\
\hline Q10 & & 643 & &, 505 & \\
\hline Q5 & & ,633 & & ,515 & 0,857 \\
\hline Q9 & & 631 & & 630 & \\
\hline Q1 & & ,585 & & ,550 & \\
\hline Q8 & &, 580 & & ,625 & \\
\hline Q4 & &, 565 & & ,364 & \\
\hline Q20 & & ,510 & & 309 & \\
\hline Q22 & & & ,686 & 619 & \\
\hline Q24 & & & 655 & ,503 & \\
\hline Q21 & & & ,637 & ,417 & 0,769 \\
\hline Q23 & & & ,596 & ,542 & \\
\hline Q2 & & & ,522 &, 530 & \\
\hline Q25 & & & 490 & 297 & \\
\hline
\end{tabular}

Fonte: Elaborado pelos autores (2019).

Conforme Hair Jr et al. (2009), elevados escores fatoriais mostram que dado item possui alta influência daquela dimensão. Segundo DeVellis (2017), o critério da significância prática sugere que itens com cargas fatoriais de 0,5 ou mais, são itens significantes por apresentarem correlação com os outros itens da mesma dimensão. Com a exclusão do item Q3, o teste evidenciou uma distribuição adequada dos itens nas 3 dimensões.

Após a definição das dimensões e da identificação da carga fatorial por item, foi realizado o Alpha de Cronbach (teste de confiabilidade interna), por dimensão. Segundo Pasquali (1999), dimensões com Alpha maior do que 0,7 são consideradas como confiáveis, principalmente em pesquisas que desenvolvem novas escalas. A partir do Alpha, conforme apresentado no Quadro 04, percebe-se que todas as três dimensões apresentam alta confiabilidade interna, tendo itens com bom nível de correlação entre eles. 
A CR é uma medida utilizada para avaliação da validade convergente (de construto). Ou seja, utilizada para medir se o instrumento é válido na extensão em que mede aquilo que se propõe a medir. Considerando os critérios de Fornell e Larcker (1981), Nunnaly e Bernstein (1994) e Tenenhaus et al. (2005), para que os construtos apresentem validade convergente satisfatória necessitam de CR superiores a 0,70. Os dados deste trabalho foram obtidos conforme o cálculo proposto por Fornell e Larcker (1981) e, dentre as três dimensões finais da escala de GCE, a dimensão 1 (Responsabilidade Corporativa) obteve 0,89, a dimensão 2 (Prestação de contas / Transparência) obteve 0,83 e a dimensão 3 (Equidade) obteve 0,77. Desta forma, a escala de GCE possui validade convergente satisfatória e de fato mede o que se propõem a medir.

A partir da realização da AFE e da redistribuição das dimensões e itens, conforme proposto pela metodologia utilizada, chegou-se ao modelo final de escala para medição de GCE, contendo os itens correspondentes das dimensões de OE com as dimensões de GC (Quadro 05).

Quadro 05 - Modelo final de escala para medição de Governança Corporativa Empreendedora.

\begin{tabular}{|c|c|c|c|}
\hline Código & Itens & Dimensões de OE & $\begin{array}{l}\text { Dimensões de } \\
\text { GC }\end{array}$ \\
\hline Q1 & $\begin{array}{l}\text { Disponibiliza informações extras, para as partes } \\
\text { interessadas, além daquelas impostas por leis / } \\
\text { regulamentos. }\end{array}$ & Proatividade & \multirow{8}{*}{$\begin{array}{l}\text { Transparência / } \\
\text { Prestação de } \\
\text { contas }\end{array}$} \\
\hline Q4 & $\begin{array}{l}\text { Permite que as empresas de auditoria } \\
\text { independente auditem processos e dados além } \\
\text { dos exigidos por lei. }\end{array}$ & $\begin{array}{l}\text { Autonomia } \\
\text { Proatividade }\end{array}$ & \\
\hline Q5 & $\begin{array}{l}\text { Desenvolve calendário anual para as principais } \\
\text { reuniões. }\end{array}$ & $\begin{array}{l}\text { Autonomia } \\
\text { Proatividade }\end{array}$ & \\
\hline Q6 & $\begin{array}{l}\text { Apresenta, as partes interessadas, resultados } \\
\text { financeiros extras, além dos obrigatórios. }\end{array}$ & Propensão ao Risco & \\
\hline Q7 & $\begin{array}{l}\text { Apresenta, as partes interessadas, os resultados } \\
\text { operacionais, incluindo os resultados com } \\
\text { inovações e melhoria contínua. }\end{array}$ & $\begin{array}{l}\text { Proatividade } \\
\text { Inovatividade }\end{array}$ & \\
\hline Q8 & $\begin{array}{l}\text { Apresenta, as partes interessadas, os objetivos } \\
\text { comerciais, incluindo os objetivos de inovação e } \\
\text { novos negócios. }\end{array}$ & $\begin{array}{l}\text { Agressividade } \\
\text { Competitiva } \\
\text { Inovatividade }\end{array}$ & \\
\hline Q9 & $\begin{array}{l}\text { Apresenta, as partes interessadas, os riscos } \\
\text { operacionais e estratégicos. }\end{array}$ & Propensão ao Risco & \\
\hline Q10 & $\begin{array}{l}\text { Contrata auditoria externa independente para } \\
\text { análise das demonstrações financeiras. }\end{array}$ & Propensão ao Risco & \\
\hline
\end{tabular}

Revista Eletrônica de Estratégia \& Negócios, Florianópolis, v.13, n. 1, jan./abr. 2020. 


\begin{tabular}{|c|c|c|c|}
\hline Código & Itens & Dimensões de OE & $\begin{array}{l}\text { Dimensões de } \\
\text { GC }\end{array}$ \\
\hline Q20 & $\begin{array}{l}\text { Estimula a participação de membros } \\
\text { independentes no conselho. }\end{array}$ & Autonomia & \\
\hline Q11 & $\begin{array}{l}\text { Desenvolve práticas em busca de melhoria } \\
\text { contínua observando as inovações do mercado. }\end{array}$ & $\begin{array}{l}\text { Agressividade } \\
\text { Competitiva } \\
\text { Inovatividade }\end{array}$ & \multirow{9}{*}{$\begin{array}{l}\text { Responsabilidade } \\
\text { corporativa }\end{array}$} \\
\hline Q12 & $\begin{array}{l}\text { Procura reduzir as externalidades negativas de } \\
\text { seus negócios. }\end{array}$ & $\begin{array}{l}\text { Agressividade } \\
\text { Competitiva }\end{array}$ & \\
\hline Q13 & $\begin{array}{l}\text { Procura aumentar as externalidades positivas de } \\
\text { seus negócios. }\end{array}$ & $\begin{array}{l}\text { Agressividade } \\
\text { Competitiva }\end{array}$ & \\
\hline Q14 & $\begin{array}{l}\text { Desenvolve o planejamento estratégico voltado } \\
\text { para a inovação. }\end{array}$ & Inovatividade & \\
\hline Q15 & $\begin{array}{l}\text { Acompanha, de forma sistemática, as práticas e } \\
\text { inovações do mercado. }\end{array}$ & Inovatividade & \\
\hline Q16 & $\begin{array}{l}\text { Estimula o desenvolvimento de ideias e projetos } \\
\text { de inovação. }\end{array}$ & $\begin{array}{l}\text { Inovatividade } \\
\text { Proatividade }\end{array}$ & \\
\hline Q17 & $\begin{array}{l}\text { Garante a funcionalidade dos sistemas de } \\
\text { gerenciamento de riscos. }\end{array}$ & Propensão ao Risco & \\
\hline Q18 & $\begin{array}{l}\text { Busca, constantemente, inovações para } \\
\text { aperfeiçoar os sistemas de controles. }\end{array}$ & Inovatividade & \\
\hline Q19 & $\begin{array}{l}\text { Estimula todos os colaboradores a trabalharem } \\
\text { de forma alinhada com as estratégias da } \\
\text { empresa. }\end{array}$ & Autonomia & \\
\hline Q21 & $\begin{array}{l}\text { Trata todos os grupos de acionistas/sócios da } \\
\text { mesma forma. }\end{array}$ & Autonomia & \multirow{6}{*}{ Equidade } \\
\hline Q22 & $\begin{array}{l}\text { Leva em conta as sugestões das partes } \\
\text { interessadas no desenvolvimento de novas } \\
\text { tecnologias / produtos / serviços. }\end{array}$ & Proatividade & \\
\hline Q23 & $\begin{array}{l}\text { Considera, na avaliação de desempenho dos } \\
\text { executivos e diretores, a atitude e o pensamento } \\
\text { inovador. }\end{array}$ & $\begin{array}{l}\text { Autonomia } \\
\text { Inovatividade }\end{array}$ & \\
\hline Q24 & $\begin{array}{l}\text { Garante os direitos e deveres das partes } \\
\text { interessadas. }\end{array}$ & Autonomia & \\
\hline Q25 & $\begin{array}{l}\text { Permite que todos os acionistas / sócios votem } \\
\text { nas assembleias / reuniões estratégicas. }\end{array}$ & $\begin{array}{l}\text { Autonomia } \\
\text { Agressividade } \\
\text { Competitiva }\end{array}$ & \\
\hline Q2 & $\begin{array}{l}\text { Facilita, as partes interessadas, o acesso a dados } \\
\text { relevantes. }\end{array}$ & Propensão ao Risco & \\
\hline
\end{tabular}

Fonte: Elaborado pelos autores (2019).

O modelo final obtido para mensuração da GCE, em empresas brasileiras de capital fechado demonstra, num primeiro momento, que os itens que caracterizam as três dimensões de GC, consideradas nesta pesquisa, expressam características, quer de forma isolada ou combinada, das dimensões que fundamentam a $\mathrm{OE}$, numa perspectiva contextual e do 
comportamento empreendedor das empresas e dos gestores pesquisadas. Em segundo, as dimensões de $\mathrm{GC}$ tanto podem estimular as dimensões da $\mathrm{OE}$, assim como estas últimas podem motivar a reconfiguração das dimensões de GC numa relação não linear.

A inserção de itens com características das dimensões de $\mathrm{OE}$, nas dimensões de GC, revela o quanto é importante as empresas terem um conselho de administração e/ou líderes que desenvolvam e incorporem a OE na condução dos negócios. Isto porque, não é suficiente as empresas terem uma estrutura de GC, mas é mister que a prática das dimensões da $\mathrm{OE}$ esteja inserida na cultura organizacional das empresas e refletida na estrutura de GC, confirmando os argumentos de Covin e Kuratko (2008), Wang (2008), Miller (2011), Covin e Wales (2012), Doorn et al. (2013), Engelen et al. (2015) e IBGC (2018). Desta forma, o sucesso e a sobrevivência em longo prazo das organizações podem ser alcançados quando a OE se tornar um fenômeno em toda a organização, inclusive nas práticas de GC. O apoio dos executivos seniores às iniciativas empreendedoras é maior quando um acionista representativo apostar e defender investimentos de longo prazo e primar pela cultura empreendedora (ZAHRA; NEUBAUM; HUSE, 2000). Para Hashimoto e Nassif (2014), as práticas de GC orientadas para a $\mathrm{OE}$, somada a atitude do gerente, podem induzir os funcionários na adoção de comportamento mais empreendedor.

Os achados de outros estudos, também reforçam a inserção das dimensões da OE nas de GC. Molokwu, Barreria e Urban (2013) identificaram que os mecanismos de GC (eficácia do conselho; conhecimento e experiência do conselho; comprometimento do conselho e; envolvimento do conselho no controle de decisões) possuíam uma correlação significativa e positiva com as dimensões de OE (inovação, propensão ao risco e proatividade); Calza, Profumo e Tutore $(2016,2017)$ constataram uma forte relação positiva entre a estrutura de propriedade com a proatividade ambiental das empresas analisadas e Olori e Sylva (2017) verificaram que os mecanismos de GC estavam positivamente relacionados com a inovatividade e a proatividade.

Percebe-se, desta forma, que as dimensões da OE podem ser incorporadas aos mecanismos de GC, como proposto na escala desenvolvida para mensurar a GCE em empresas brasileiras de capital. 


\section{CONCLUSÃO}

Este trabalho buscou alcançar o objetivo de desenvolver uma escala para medição da GCE em empresas brasileiras de capital fechado, partindo de conceitos teóricos apresentados pelo IBGC (2015), OECD (2015) e Lumpkin e Dess (1996). Segundo a literatura, quatro dimensões fundamentam a GC: transparência, prestação de contas, responsabilidade corporativa e equidade. Todavia, após o desenvolvimento da escala inicial e da realização dos testes estatísticos, foi observada correlação entre os itens das dimensões de prestação de contas e transparência, o que motivou os pesquisadores a realizarem a junção das duas dimensões, resultando ao final das análises estatísticas, apenas três dimensões.

A responsabilidade corporativa, para refletir características das dimensões da $\mathrm{OE}$, precisa estar caracterizada pelo pensar e pelo agir estratégico, suportada por um efetivo monitoramento das decisões e das ações da administração pela diretoria e da responsabilidade da diretoria perante a empresa e os acionistas. Ela foi caracterizada no ambiente organizacional das empresas pesquisadas pelos seguintes itens: melhoria contínua e inovações de mercado; redução de externalidades negativas e aumento das positivas; planejamento estratégico voltado para a inovação; práticas e inovações do mercado e inovações dos sistemas de controle; alinhamento das ações; funcionalidade dos sistemas de gerenciamento de riscos e; desenvolvimento de ideias e projetos de inovação.

A equidade expressa o tratamento justo e isonômico de todos os sócios e demais partes interessadas (stakeholders): direitos, deveres, necessidades, interesses e expectativas. A GC deve assegurar a equidade dos grupos perante os objetivos da sociedade e promover o desenvolvimento econômico de todos, especialmente dos grupos mais vulneráveis. A equidade foi caracterizada nas empresas pesquisadas pelos itens, como segue: tratamento igualitário de todos, bem como os direitos e deveres; valorização das sugestões das partes interessadas no desenvolvimento das ações; valorização do desempenho dos executivos e diretores, da atitude e do pensamento inovador; direito a voto aos acionistas e sócios e pela permissão ao acesso a dados relevantes pelas partes interessadas.

A transparência demonstra o quanto a empresa está disposta em disponibilizar para as partes interessadas as informações extras, além daquelas impostas por disposições de leis 
ou regulamentos. A prestação de contas (accountability) mostra que os agentes de GC devem prestar contas de sua atuação de modo claro, conciso, compreensível e tempestivo, assumindo integralmente as consequências de seus atos e omissões e atuando com diligência e responsabilidade no âmbito dos seus papéis. A transparência/prestação de contas (accountability) foi caracterizada nas empresas pesquisadas pelos seguintes itens: disponibilização de informações extras; participação de membros independentes no conselho; realização de auditorias, calendário anual e resultados operacionais; resultados financeiros extras, riscos operacionais e estratégicos e auditoria externa); objetivos comerciais, de inovação e de novos negócios.

Este trabalho possui relevância por ser o primeiro estudo a desenvolver uma escala para medição de GCE em empresas brasileiras de capital fechado.

Algumas limitações e oportunidades de novos estudos são aparentes neste trabalho, como a aplicação da mesma escala em outra amostra, realização da análise fatorial confirmatória, estudo e compreensão da escala aplicada em organizações de um mesmo setor e validação em outros trabalhos da fusão das dimensões de prestação de contas e transparência.

\section{REFERÊNCIAS}

AGHION, P.; VAN REENEN, J.; ZINGALES, L. Innovation and institutional ownership. American Economic Review, v. 103, n. 1, p. 277-304, 2013.

AGLIETTA, M.; REBÉRIOUX, A. Corporate governance Adrift: a critique of shareholder value. Northamton: Edward Elgar Publishing, Inc. 2005.

AGUILERA, R.V.; DESENDER, K.; BEDNAR, M. K.; LEE, J. H. Connecting the dots: bringing external corporate governance into the corporate governance puzzle. Academy of Management Annals, v. 9, n. 1, p. 483-573, 2015.

AGUILERA, R.V.; FILATOTCHEV, I.; GOSPEL, H.; JACKSON, G. An organizational approach to comparative corporate governance: Costs, contingencies, and complementarities.

Organization Science, v.19, n. 3, p. 475-492, 2008.

AGUILERA, R.V.; JACKSON, G. Comparative and international corporate governance. The Academy of Management Annals, v. 4, n. 1, p. 485-556, 2010. 
AGUILERA, R.V.; MARANO, V.; HAXHI, I, International Corporate Governance: A review and opportunities for future research. Journal of International Business Studies, v. 50, n. 4, p. 457-498, 2019.

AHMAD, S.; OMAR, R. Basic corporate governance models: a systematic review. International Journal of Law and Management, v. 58, n. 1, p.73-107, 2016.

ANDERSON D. W.; MELANSON S. J.; MALY, J. The evolution of corporate governance; power redistribution brings boards to life. Corporate Governance: an International Review, v. 15, n. 5, p. 780-797, 2007.

ASENSIO-LÓPEZ, D.; CABEZA-GARCÍA, L.; GONZÁLEZ-ÁLVAREZ, N. Corporate governance and innovation: a theoretical review. European Journal of Management and Business

Economics, v. 28, n. 3, p. 266-284. 2019.

BHAGAT, S.; BOLTON, B. Corporate governance and firm performance. Journal of Corporate Finance, v. 14, n. 3, p. 257-273, 2008.

BENNER, M. J. Securities analysts and incumbent response to radical technological change: Evidence from digital photography and internet telephony. Organization Science, v. 1, n. 1, p. 42-62, 2010.

BENNER, M. J.; RANGANATHAN, R. Offsetting illegitimacy? How pressures from securities analysts influence incumbents in the face of new technologies. Academy of Management Journal, v. 55, n. 1, p. 213-233, 2012.

BLOCK, D.; GERSTNER, A. One-tier vs. two-tier board structure: a comparison between the United States and Germany. 2016. Disponível em:

http://scholarship.law.upenn.edu/cgi/viewcontent.cgi?article=1001\&context=fisch_2016. Acesso em: 13 ago. 2018.

BOTTENBERG, K.; TUSCHKE, A.; FLICKINGER, M. Corporate governance between shareholder and stakeholder orientation: lessons from Germany. Journal of Management Inquiry, v. 26, n. 2, p. 165-180, 2017.

CALZA, F.; PROFUMO, G.; TUTORE, I. Boards of directors and firms' environmental proactivity. Corporate Governance and Organizational Behavior Review, v. 1, n. 1, p. 52-64, 2017.

CALZA, F.; PROFUMO, G.; TUTORE, I. Corporate ownership and environmental proactivity. Business Strategy and the Environment, v. 25, n. 6, p. 369-389, 2016.

CERNAT, L. The emerging European corporate governance model: Anglo-Saxon, Continental, or still the century of diversity? Journal of European Public Policy, v. 11, n. 1, p. 147-166, 2004.

CHEVALIER, J. A. Capital structure and product-market competition: Empirical evidence from the supermarket industry. American Economy Review, v. 85, n. 3, p. 415-435, 1995. 
CHRISTOPHER, J. Corporate governance: a multi-theoretical approach to recognizing the wider influencing forces impacting on organizations. Critical Perspectives on Accounting, v. 21, n. 8, p. 683-695, 2010.

CLAESSENS, S.; YURTOGLU, B. B. Corporate governance in emerging markets: a survey. Emerging Markets Review, v.15, n. 1, p. 1-33, 2013.

COVIN, J. G.; KURATKO, D. F. The concept of corporate entrepreneurship. In: NARAYANAN, V.; O'CONNOR, G. (Eds.). The Blackwell encyclopedia of technology and innovation management. Oxford, UK: Blackwell Publishers, 2008.

COVIN, J. G.; SLEVIN, D. P. A conceptual model of entrepreneurship as firm behavior. Entrepreneurship Theory and Practice, v. 16, n. 1, p. 7-25, 1991.

COVIN, J. G.; SLEVIN, D. P. Strategic management of small firms in hostile and benign environments. Strategic Management Journal, v. 10, n. 1, p. 75-87, 1989.

COVIN, J. G.; SLEVIN, D. P. The influence of organization structure on the utility of an entrepreneurial top management style. Journal of Management Studies, v. 25, n. 3, p. 217234, 1988.

COVIN, J. G.; WALES, W. J. The measurement of entrepreneurial orientation. Entrepreneurship: Theory and Practice, v. 36, n. 4, p. 677-702, 2012.

CUERVO-CAZURRA, A.; RAMAMURTI, R. Home country underdevelopment and internationalization: Innovation-based and escape-based internationalization. Competitiveness Review, v. 27, n. 3, p. 217-230, 2017.

DAINES, R. M.; GOW, I. D.; LARCKER, D. F. Rating the ratings: How good are comercial governance ratings? Journal of Financial Economics. v. 98, p. 439-461, 2010.

DE CLEYN, S. H.; BRAET, J. Do board composition and investor type influence innovativeness in SMEs? International Entrepreneurship and Management Journal, v. 8, p. 85-308, 2012.

DESS, G. G.; LUMPKIN, G. T. The role of entrepreneurial orientation in stimulating effective corporate entrepreneurship. The Academy of Management Executive, v. 19, n. 1, p.147156, 2005.

DEVELLIS, R. F. Scale development: theory and application. Fourth edition. Los Angeles, CA: Sage Publications, 2017.

DOORN, S. V.; JANSEN, J. J. P.; BOSCH, F. A. V. D.; VOLBERDA, H. W. Entrepreneurial orientation and firm performance: Drawing attention to the senior team. Journal of Product Innovation Management, v. 30, n. 5, p. 821-836. 2013.

DORFF, M. Indispensable and other myths: why the CEO pay experiment failed and how to fix it: University of California Press, 2014. 
EDMOND, V. P.; WIKLUND, J. The historic roots of entrepreneurial orientation research. In: Historical Foundations of Entrepreneurship Research. Edward Elgar Publishing Ltd., 2010. p. 142-160.

ELING, M.; MAREK, S. Corporate governance and risk taking: evidence from the U.K. And German insurance markets. The Journal of Risk Insurance, v. 91, n. 3, p. 653-682, 2014.

ENGELEN, A.; GUPTA, V.; STRENGER, L.; BRETTEL, M. Entrepreneurial orientation, firm performance, and the moderating role of transformational leadership behaviors. Journal of Management, v. 41, n. 4, p. 1069-1097, 2015.

FAMA, E. F.; JENSEN, M. C. Separation of ownership and control. Journal of Law and Economics, v. 26, n. 2, p. 301-325. 1983.

FÁVERO, L. P.; BELFIORE, P.; SILVA, F. L. da; CHAN, B. L. Análise de dados: modelagem multivariada para tomada de decisões. Rio de Janeiro: Elsevier, 2009.

FERDOUS, C. F.; RAHMAN, S. M. M. Corporate governance index of banks in Bangladesh and its determinants. Journal of Business and Management, v. 19, n. 12, p. 76-91, 2017.

FOHLIN, C. The history of corporate ownership and control in Germany. In: Morck, R. K. (Ed.). A history of corporate governance around the world: Family business groups to professional managers. Cambridge, MA: National Bureau of Economic Research. 2005. p. 223-282.

FORNELL, C.; LARCKER, D. F. Evaluating structural equations models with unobservable variables and measurement error. Journal of Marketing, v. 18, n. 1, p. 39-50, 1981.

GABRIELSSON, J.; HUSE, M. Context, behavior and evolution-challenges in research on boards and governance. International Studies in Management and Organization, v. 34, n. 2, p. 11-36, 2004.

GARCIA-CASTRO R, AGUILERA R. V. Incremental value creation and appropriation in a world with multiple stakeholders. Strategic Management Journal, v. 36, n. 1, p. 137-147, 2015.

GONZALES-BUSTOS, J. P.; HERNÁNDEZ-LARA, A. B. Corporate governance and innovation: a systematic literature review. Corporate Ownership and Control Journal, v. 13, n. 3, p. 33-45, 2016.

HAGEN, A., EMMANUEL, T. AND ALSHARE, K. Major determinants of entrepreneurship in mid-size companies: Empirical investigation. In: Southwest Decision Sciences Institute, 2005 Conference Proceedings. Dallas, USA, 3-4, Mar. 2005. p. 468-478. Disponível em: <http://swdsi.org/swdsi05/Proceedings05/paper_pdf/Entrepreneurship\%20by\%20AHagan\%20T-Emmanuel\%20K-Alshare\%20(F2B2).pdf>. Acesso em: 15 dez. 2019.

HAIR JR. J. F.; WILLIAM, B.; BABIN, B.; ANDERSON, R. E. Análise multivariada de dados. 6. ed. Porto Alegre: Bookman, 2009. 
HALL, B. H.; ORIANI, R. Does the market value R\&D investment by European firms? Evidence from a panel of manufacturing firms in France, Germany, and Italy. International Journal of Industrial Organization, v. 24. n. 5, p. 971-993, 2006.

HANAZAKI, M.; LIU, Q. Corporate governance and investment in East Asian firms: empirical analysis of family-controlled firms. Journal of Asian Economics, v. 18, n. 1, p. 76-97, 2007.

HASHIMOTO, M.; NASSIF, V. M. J. Inhibition and encouragement of entrepreneurial behavior: antecedents analysis from managers' perspectives. Brazillian Administration Review, Rio de Janeiro, v. 11, n. 4, p. 385-406, 2014.

HESS, K.; GUNASEKARAGE, A.; HOVEY, M. State-dominant and non-state-dominant ownership concentration and firm performance: evidence from China. International Journal of Managerial Finance, v. 6. n. 4, p. 264-289. 2010.

HUNG, H.; MONDEJAR, R. Corporate directors and entrepreneurial innovation: an empirical study. The Journal of Entrepreneurship, v. 14, n. 2, p. 117-129, 2005.

IBGC - INSTITUTO BRASILEIRO DE GOVERNANÇA CORPORATIVA. Manual de análises e tendências - Inovação. São Paulo: Saint Paul, 2018.

IBGC - INSTITUTO BRASILEIRO DE GOVERNANÇA CORPORATIVA. Código das melhores práticas de governança corporativa. ed. 5. São Paulo: IBGC, 2015.

IBGC - INSTITUTO BRASILEIRO DE GOVERNANÇA CORPORATIVA. Código das melhores práticas de governança corporativa. Instituto Brasileiro de Governança Corporativa. São Paulo: IBGC, 2009.

JENSEN, M.; MECKLING, W. Theory of the firm: managerial behavior, agency costs and ownership structure. Journal of Financial Economics, v. 3, n. 4, p. 305-360, 1976.

JOSLIN, R.; MÜLLER, R. The relationship between project governance and project success. International Journal of Project Management, v. 34, n. 4, p. 613-626, 2016.

KAISER, H. F. The varimax criterion for analytic rotation in factor analysis. Psychometrika, v. 23, n. 3, p. 187-200, 1958,

KALEZIĆ, Z. Corporate governance and firm performance with special reference to the banking system: empirical evidence from Monetengro. Journal of Central Banking Theory and Practice, v.1, n. 2, p. 19-54, 2012.

KOSTYUK, A.; MOZGHOVYI, Y.; GOVORUN, D. Corporate governance, ownership and control: A review of recent scholarly research. Corporate Board: Role, Duties and Composition, $v$. 14, n. 1, p. 50-56, 2018.

LEE, P. M.; O'NEILL, H. M. Ownership structures and R\&D investments of US and Japanese firms: agency and stewardship perspectives. Academy of Management Journal, v. 46, n. 2 , p. 212-225. 2003. 
L'HUILLIER, B. M. What does corporate governance actually mean? Corporate Governance, v. 14, n. 3, p. 300-319, 2014.

LUMPKIN, G. T; DESS, G. G. Clarifying the entrepreneurial orientation construct and linking it to performance. Academy of Management Review, v. 21, n. 1, p. 135-172, 1996.

MALLIN, C. A. Corporate governance development in the UK. Edward Elgar Publishing, Cheltenham, 2011.

MCGUIRE, J.; DOW, S. Japanese keiretsu: past, present, future. Asia Pacific Journal of Management, v. 26, n. 2, p. 333-351, 2009.

MENDIETA, A. C.; MARTENS, C. D. P.; BENTO, F. O.; LACERDA, F. M. O uso de tecnologias móveis e a orientação empreendedora: estudo em uma organização decapitalização. Revista Eletrônica de Estratégia \& Negócios, Florianópolis, v.6, n.3, 2013.

MILLER, D. M. (1983) revisited: A reflection on EO research and some suggestions for the future. Entrepreneurship: Theory \& Practice, v. 35, n. 5, p. 873-894. 2011.

MILLER, D. M. The correlates of entrepreneurship in three types of firms. Management Science, v. 29, n. 7, p. 770-791, 1983.

MILLER, D. M.; FRIESEN, P.H. Innovation in conservative and entrepreneurial firms: two models of strategic momentum. Strategic Management Journal, v. 3, n. 1, p. 1-25, 1982.

MINETTI, R.; MURRO, P.; PAIELLA, M. Ownership structure, governance, and innovation: evidence from Italy. European Economic Review, v. 80, p. 165-193, 2015.

MOLOKWU, V.; BARRERIA, J.; URBAN, B. Entrepreneurial orientation and corporate governance structures at the firm level in the South African oil and gas industry. SA Journal of Human Resource Management, v. 11, n. 1, p. 1-15, 2013.

NERANTZIDIS, M. A multi-methodology on building a corporate governance index from the perspectives of academics and practitioners for firms in Greece. Corporate Governance, $v$. 16, n. 2, p. 295-329, 2016.

NUNNALLY, J. C.; BERNSTEIN, I. H. Psychometric Theory. New York, McGraw-Hill, 1994.

OECD - ORGANISATION FOR ECONOMIC CO-OPERATION AND DEVELOPMENT. OECD Corporate Governance Factbook 2019. 2019. Disponível em:

<www.oecd.org/corporate/corporate-governance-factbook.htm>. Acesso em: 14 nov. 2019.

OECD - ORGANISATION FOR ECONOMIC CO-OPERATION AND DEVELOPMENT. G20/OECD principles of corporate governance. Paris: OECD Publishing, 2015. Disponível em: <https://www.oecd.org/daf/ca/Corporate-Governance-Principles-ENG.pdf.> Acesso em: 14 nov. 2019. 
OLORI, W. O.; SYLVA, W. Corporate governance system and entrepreneurial orientation in the banking sector: evidence from a developing country. International Journal of Innovation and Economics Development, v. 2, n. 6, p. 29-48, 2017.

OSINSKI, M.; ROMAN, D. J.; PEREIRA, M. F. Responsabilidade social e governança corporativa em uma construtora. Revista Eletrônica de Estratégia \& Negócios, Florianópolis, v. 9, n. 1, p. 181-203, 2016.

PASQUALI, L. Análise fatorial: um manual teórico-prático. Brasília: Editora da UnB, no prelo, 1998.

PESTANA, M. H.; GAGEIRO, J. N. Análise de dados para ciências sociais: a complementariedade do SPSS. Edições Sílabo: Lisboa, 2005

RAMLY, Z. Corporate governance, shareholder monitoring and cost of debt in Malaysia. International Journal of Economics and Management Engineering, v. 7, n. 4, p. 1062-1073, 2013.

ROBINSON, P. B.; STIMPSON, D. V.; HUEFNER, J. C.; HUNT, H. K. An attitude approach to the prediction of entrepreneurship. Entrepreneurship Theory \& Practice, v. 15, n. 4, p. $13-30$, 1991.

ROSSITER, J. R. The C-OAR-SE procedure for scale development in marketing. International Journal of Research in Marketing, v. 19, n. 4, p. 305-335, 2002.

SAKAWA, H.; MORIYAMA, K.; WATANABEL, N. Relation between top executive compensation structure and corporate governance: Evidence from Japanese public disclosed data.

Corporate Governance: An International Review, v. 20, n. 6, p. 593-608, 2012.

SHAPIRO, D.; TANG, Y.; WANG, M.; ZHANG, W. The effects of corporate governance on innovation in Chinese firms. Journal of Chinese Economic and Business Studies, v. 13, n. 4, p. 311-335. 2015.

SIPOS, G. L. The influence of corporate governance on innovation dimensions - case study of European emergent countries. Economic Computation and Economic Cybernetics Studies and Research, v. 51, n. 4, p. 159-172, 2017.

SOLOMON, J.; SOLOMON, A. Corporate governance and accountability. John Wiley and Sons Ltd.: West Sussex, 2004.

TABACHNICK, B. G.; FIDELL, L. S. Using multivariate statistics. New York: Harper Collins, 1996.

TAN, W. L.; TAN, T. M. The impact of corporate governance on value creation in entrepreneurial firms. Rencontres de St-Gall 2004, Appenzell. Research Collection Lee Kong Chian School of Business, 2004. Disponível em:

https://ink.library.smu.edu.sg/lkcsb_research. Acesso em: 11 dez. 2019. 
TENENHAUS, M.; VINZI, V.; CHATELIN, Y.; LAURO, C. PLS path modeling. Computacional statistics \& Data Analysis, v. 48, p. 159-205, 2005

TSENG, M-L. et al. Improving performance of green innovation practices under uncertainty. Journal of Cleaner Production, v. 40, p. 71-82, 2013.

TYLECOTE, A.; VISINTIN, F. A new taxonomy of national systems of corporate governance. In: MJOSET, L.; CLAUSEN, T. Capitalisms compared. Amsterdam: Elsevier, 2007. p. 71-122.

VASILESCU, G. L. Corporate governance in developing and emerging countries: the case of Romania. MPRA Paper, n. 10998, p. 01-12, oct., 2008. Disponível em: http://mpra.ub.unimuenchen.de/10998/. Acesso em: 22 ago. 2018.

WANG, C. L. Entrepreneurial orientation, learning orientation, and firm performance. Entrepreneurship Theory and Practice, v. 32, n 4, p. 635-656, 2008.

WÓJCIK-KARPACZ, A. The Researchers proposals: what is the entrepreneurial orientation? Managing innovation and diversity in knowledge society through turbulent time.

Proceedings of the MakeLearn and TIIM Joint International Conference 2016. Disponível em: <http://www.toknowpress.net/ISBN/978-961-6914-16-1/MakeLearn2016. pdf>. Acesso em: 19 dez. 2019.

ZAHRA, S. A. Governance, ownership, and corporate entrepreneurship: the moderating impact of industry technological opportunities. The Academy of Management Journal, v. 39, n. 6, p.1713-1735, 1996.

ZAHRA, S. A.; NEUBAUM, D. O.; HUSE, M. Entrepreneurship in medium-size companies: exploring the effects of ownership and governance systems. Journal of Management, v. 26, n. 5, p. 947-976, 2000.

ZHANG, Y.; GIMENO, J. Earnings pressure and long-term corporate governance: can longterm-oriented investors and managers reduce the quarterly earnings obsession?

Organization Science, v. 27, n. 2, p. 1-19, 2016. 